\title{
Voltage profile and power quality improvement in photovoltaic farms integrated medium voltage grid using dynamic voltage restorer
}

\author{
Abdelkrim Benali ${ }^{1}$, Mounir Khiat ${ }^{2}$, Mouloud Denai ${ }^{3}$ \\ ${ }^{1,2}$ SCAMRE Laboratory, Department of Electrical Engineering, M-Audin Ecole polytechnique, Algeria. \\ ${ }^{2}$ University of Hertfordshire, United Kingdom
}

\begin{abstract}
Article Info
Article history:

Received Oct 9, 2019

Revised Nov 9, 2019

Accepted Feb 15, 2020

Keywords:

DVR

Inverter (VSI)

Photovoltaic

Power factor

Reactive power

ABSTRACT

In this paper, we have presented a simulation study to analyze the power quality of three phases medium voltage grid connected with distribution generation (DG) such as photovoltaic (PV) farms and its control schemes. The system uses two-stage energy conversion topology composed of a DC to DC boost converter for the extraction of maximum power available from the solar PV system based on incremental inductance technique and a three-level voltage source inverter (VSI) to connect PV farm to the power grid. To maintain the grid voltage and frequency within tolerance following disturbances such as voltage swells and sags, a fuzzy logic-based Dynamic Voltage Restorer is proposed. The role of the DVR is to protect critical loads from disturbances coming from the network. Different fault conditions scenarios are tested and the results such as voltage stability, real and reactive powers, current and power factor at the point of common coupling (PCC) are compared with and without the DVR system.
\end{abstract}

Voltage stability

This is an open access article under the CC BY-SA license.

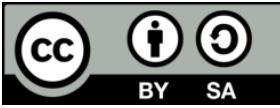

Corresponding Author:

Abdelkrim Benali,

Department of Technology,

NOUR Bachir University Center, El Bayadh, Algeria..

Email: benaliabd@yahoo.fr

\section{INTRODUCTION}

The capacity of renewable energy is set to increase by 50\% between 2019 and 2024 in the latest forecasts of the International Energy Agency for 5 years and solar PV controls the largest proportion of them. This represents an increase of 1,200 GW, which corresponds to the total installed capacity of the United States today. Solar PV alone represents about $60 \%$ of this projected growth [1]. In 2016; nearly $80 \mathrm{GW}$ of PV panels were installed worldwide [2]. This corresponds, in average, to the installation of more than 31,000 PV panels per hour and represents a growth of $48 \%$ compared to 2015. The global installed capacity for solar PV reached $303 \mathrm{GW}$ in 2016. The orientation of China's energy policies towards renewable energies has made it the world leader in solar PV with installed capacity in 2018 of $45 \mathrm{GW}$ (cumulative capacity of $176 \mathrm{GW}$ ), India is the second global leader with $11 \mathrm{GW}$ and the United States comes in 3rd with $10.6 \mathrm{GW}$, closely followed by Japan with a cumulative of $56 \mathrm{GW}$. Germany is fourth with $45.4 \mathrm{GW}[1,3]$. Solar is an inherently time-varying source of energy due to the variability of the sun's irradiance throughout the day and across the seasons. Thus, the integration of such stochastic and unpredictable renewable energy sources into the network poses new challenges to grid operators in maintaining a stable secure energy supply. This can cause power quality issues due to the appearance of phenomena like flickers, fault ride through, voltage dips / swells, high voltage ride-through (HVRT) and low voltage ride through (LVRT), harmonic resonance, phase 
imbalance or low power factor which are among the major concerns of power utilities and regulators. Power quality issues will become crucial as renewable energy sources penetration increases [3-5].

In practice, voltage sag and harmonics are the major problems in a power system. They can cause malfunctioning or tripping of equipment and many other problems on the power system. Electricity generation from solar energy has been one of the fastest growing technology and has become, globally, the most promising renewable energy resource [3]. In [6], the authors applied a Dynamic Voltage Restorer (DVR) to enhance the power quality and the low voltage ride through (LVRT) capability of a hybrid distribution generation (DG) system connected to a three-phase medium-voltage network. In [7], a comprehensive review of several control schemes to enhance the LVRT capability of grid-feeding converters is presented. The paper also discusses the respective advantages and limitations of each control strategy. The authors in [8-9], discussed the use of PV-based DVR to compensate and safeguard the power quality and maintain voltage stability between the PCC and the distribution network. A novel control strategy of the DVR is proposed for the mitigation voltage disturbances such as sags and swells. In [10-14], the implementation of a Dynamic Voltage Restorer for voltage quality improvement in the system integrated with Distributed generation (DG). The authors highlight the ways to speed up the technology development towards the extensive integration of the DVR in the near future. As mentioned above; the DVR can be integrated into the network in several control configurations to overcome the problems related to power quality. In this work, the DVR is integrated to a power grid connected to a PV farm in order to mitigate the intermittency and variability of solar energy and overcome grid faults caused by voltage sags and swell at the PCC. The proposed DVR control scheme employs a fuzzy logic controller and an in-phase compensation technique. The designed DVR and the electric system are evaluated under various fault conditions.

The remaining of the paper is organized as follows: Section 2 describes the proposed topology of the PV farms connected to the DVR and tied to the grid. In Section 3, the structure of DC to DC and DC to AC converters models are developed. The DVR topology and its basic control scheme are described in Section 4. Section 5 presents a series of simulation results to demonstrate the improvement of voltage stability and power controllability with the proposed DVR circuit. Conclusions of the paper are summarized in Section 6.

\section{PROPOSED SIMULATED SCENARIOS AND NETWORK TOPOLOGY ESEARCH METHOD}

The proposed power system model is shown in Figure 1. It is composed of five PV farms of $100 \mathrm{~kW}$ each. The PV farms are interfaced to the distribution grid through a three phase PMW inverter and threephase alternating current choke filter.

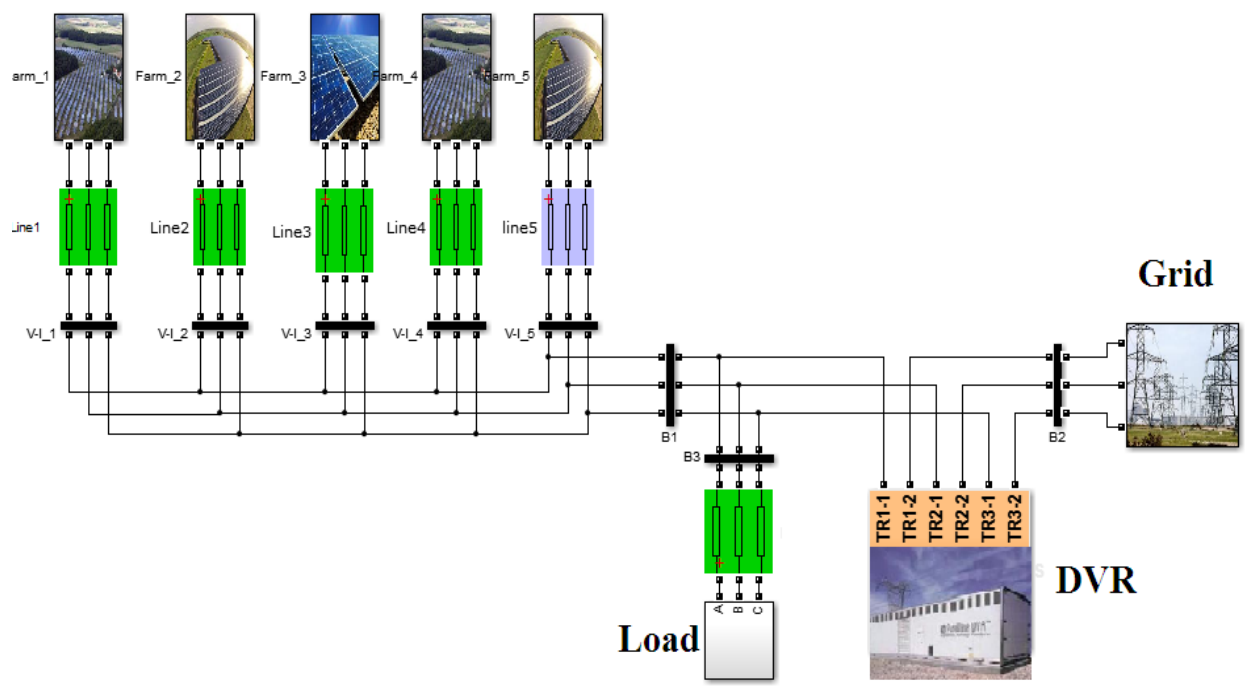

Figure 1. Power system model studied including five PV farms integrated to grid and connected to the DVR.

The five PV farms have the same power rating and same topology. However, each farm is simulated with different solar irradiation as shown in Figure 2. 


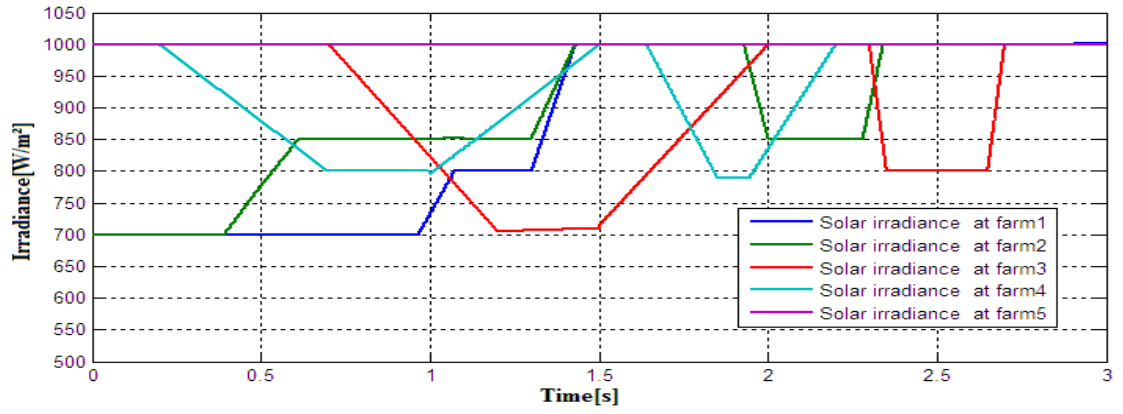

Figure 2.Solar irradiances of the five PV farms.

\section{MODELING OF THE PV CELL AND CONVERTERS}

The PV cell model used in the paper is based on the two-diode equivalent circuit model shown in Figure 3.

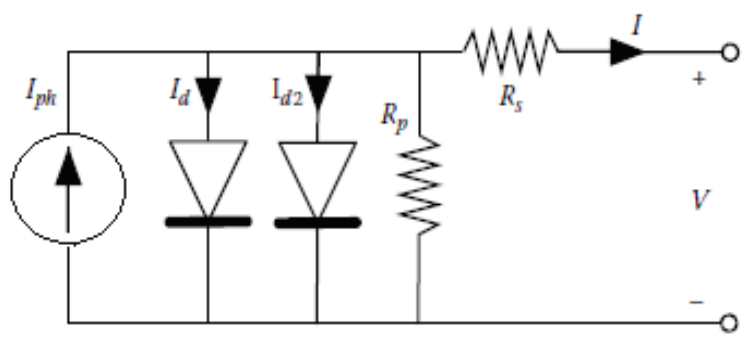

Figure 3. PV cell equivalent circuit model [15]

The expression of the I-V curve describing the equivalent circuit shown of Figure 3 is given in terms of the total cell current [15]:

$$
\begin{aligned}
& I=I_{\mathrm{ph}}-I_{\mathrm{d} 1}-I_{\mathrm{d} 2}-\frac{V+\mathrm{IR}_{s}}{R p} \\
& I=I_{\mathrm{ph}}-I_{\mathrm{s} 1}\left(e^{q \frac{V+\mathrm{IR}_{S}}{\eta \mathrm{kT}}-1}\right)-I_{\mathrm{s} 2}\left(e^{q \frac{V+\mathrm{IR}_{s}}{\eta \mathrm{kT}}-1}\right)
\end{aligned}
$$

$\eta$ is the ideality factor.

The PV Module and PV field are modeled by considering that all the PV cells are extremely identical and have the same ambient conditions. If there are $\mathrm{N}_{\mathrm{s}}$ cells connected in series and $\mathrm{N}_{\mathrm{p}}$ in parallel then the series resistance $R_{s}$ and parallel resistance $R_{p}$ are scaled by a factor of $N_{s} / N_{p}$ as shown in equation (3) below [15]:

$$
R_{\mathrm{p}, \text { field }}=\frac{N_{S}}{N_{p}} \cdot R_{\mathrm{p}, \text { cell }}
$$

The PV power conversion is controlled by a Maximum Power Point Tracking algorithm to extract the maximum power via DC to DC converter of a high efficiency that acts as an optimal electrical load for a PV cell, most often for array or solar panel, and converts the power into a voltage or current level that is better suited to the load that the system is designed to provide. PV cells have a single operating point where the current (I) and voltage $(\mathrm{V})$ values of the cell result in maximum output power [16]. Figure 4 shows the I-V characteristic of the PV module. The short-circuit current, open-circuit voltage and maximum power points are highlighted on the I-V curves. 

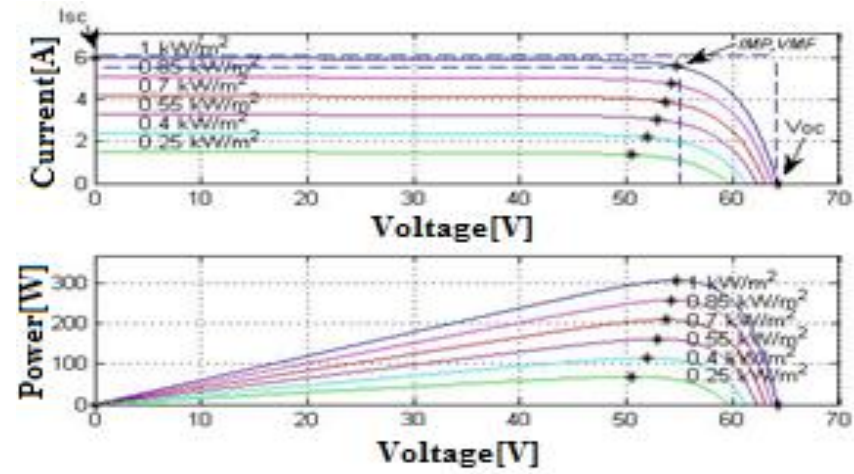

Figure 4. I-V and P-V curves of a Photovoltaic module for varying solar irradiation levels at a temperature of $25^{\circ} \mathrm{C}$

As shown in Figure 4, the MPP defines the maximum power $\mathrm{P}_{\mathrm{MP}}=\mathrm{V}_{\mathrm{MP}} \mathrm{I}_{\mathrm{MP}}$ obtainable from the $\mathrm{PV}$ module. The voltage $V_{M P}$ is found by solving:

$$
\left.\frac{\mathrm{dP}_{\mathrm{pv}}}{\mathrm{dV_{ \textrm {pv } }}}\right|_{V=V_{\mathrm{MP}}}=\left.\frac{d\left(I_{\mathrm{pv}} V_{\mathrm{pv}}\right)}{\mathrm{d} V_{\mathrm{pv}}}\right|_{V=V_{\mathrm{MP}}}=1+\left.V_{\mathrm{pv}} \frac{\mathrm{dI}_{\mathrm{pv}}}{\mathrm{dV} V_{\mathrm{pv}}}\right|_{V=V_{\mathrm{MP}}}=0
$$

The current $\mathrm{I}_{\mathrm{MP}}$ is then determined by evaluating Equation (1) at $\mathrm{V}=\mathrm{V}_{\mathrm{MP}}[17]$.

The PV array considered in this simulation study consists of seven (7) modules in series and (47) parallel strings in order to generate $100 \mathrm{~kW}$ at solar irradiance of $1000 \mathrm{~W} / \mathrm{m}^{2}$ and an output DC voltage of 380V. There are several MPPT methods available in the literature [18].In this work, the Incremental Conductance (InC) algorithm which can be regarded as an improved version of the popular $\mathrm{P} \& \mathrm{O}$ is employed[15]. This method was proposed to handle rapidly changing atmospheric conditions [19].

The gradient of the power curve is:

$$
\begin{aligned}
& \frac{\mathrm{dP} \mathrm{PV}_{\mathrm{PV}}}{\mathrm{dV}_{\mathrm{PV}}}=0 \Rightarrow \frac{\mathrm{dI}_{\mathrm{PV}}}{\mathrm{dV}_{\mathrm{PV}}}=\frac{I_{\mathrm{PV}}}{V_{\mathrm{PV}}} \\
& \frac{\mathrm{dP} \mathrm{PV}}{\mathrm{d} V_{\mathrm{PV}}}=\frac{d\left(I_{\mathrm{PVV}} V_{\mathrm{PV}}\right)}{\mathrm{d} V_{\mathrm{PV}}}=I_{\mathrm{PV}}+V_{\mathrm{PV}} \frac{\mathrm{dI}_{\mathrm{PV}}}{\mathrm{d} V_{\mathrm{PV}}}
\end{aligned}
$$

Multiplying both sides by $1 / \mathrm{V}_{\mathrm{PV}}$ leads to:

$$
\frac{1}{V_{\mathrm{PV}}} \frac{\mathrm{dP}_{\mathrm{PV}}}{\mathrm{dV}_{\mathrm{PV}}}=\frac{I_{\mathrm{PV}}}{V_{\mathrm{PV}}}+\frac{\mathrm{dI}_{\mathrm{PV}}}{\mathrm{dV}_{\mathrm{PV}}}=G_{\mathrm{PV}}+\mathrm{dG}_{\mathrm{PV}}
$$

Where $\mathrm{G}$ and $\mathrm{dG}$ denote the conductance and incremental conductance respectively.

The DC to DC converter is used to change the voltage level of a DC source. The inductor and capacitors parameter values in the boost converter circuit are: $\mathrm{C}=0,1 \mathrm{mF}, \mathrm{C} 1=\mathrm{C} 2=12 \mathrm{mF}, \mathrm{L} 1=5 \mathrm{mH}$. Based on the instantaneous values of the current and voltage, the duty cycle of the boost DC-DC converter is continuously adjusted by the MPPT controller to ensure that the PV generator always operates at its MPP for any irradiance and temperature conditions [15]. In high voltage and high power applications, it is suitable to operate with high voltages to keep the currents within reasonable levels. This needs the DC bus voltage $\mathrm{V}_{\mathrm{d}}$ to exceed the voltage ratings of the converter power switches [20]. Therefore, integration of renewable energy can cause serious power quality issues. Among these, the harmonics generated by in inverters and injected into grid are of major concern [21-23]. For linear modulation (i.e. for amplitude modulation factor $\mathrm{m}_{\mathrm{a}} \leq 1$ ) the amplitude of the first harmonics changes linearly accordingly to the change of the amplitude modulation factor, so the expression for phase voltage has the form:

$$
V_{1, \mathrm{LN}}=m_{a} \frac{V_{\mathrm{DC}}}{2}
$$




\section{DVR TOPOLOGY}

The Dynamic Voltage Restorer consists of a Voltage Source Converter (VSC), a switching control scheme, an energy storage device and a coupling transformer connected in series with the AC system. The DVR can be applied to a variety of power quality and reliability problems including dip voltage compensation, voltage unbalance, voltage regulation, harmonic isolation, power factor correction and power outages. Therefore, it can provide protection against any sags, swells, and large fluctuations in the alternating current line voltage [24]. The DVR injects a three phase AC voltage in series and synchronized with the distribution feeder voltages of the AC power system. The amplitude and phase of the injected voltage can be varied to regulate the exchange of active and reactive powers between the DVR and power system within predetermined limits negative (power absorption) and positive (power injection) [24]. The DVR can provide harmonic isolation to prevent harmonics in the source voltage from reaching the load. In addition, the DVR also provides voltage balancing and voltage regulation [24].

The general configuration of a DVR includes:

- Injection/Booster transformer

- Harmonic filter

- Storage device

- $\quad$ Voltage Source Converter

- DC charging circuit

- Control and Protection system

The DVR inject a voltage amplitude can be expressed as:

$V_{\mathrm{DVR}}=V_{\mathrm{Lo}}+Z_{\mathrm{TH}} I_{\mathrm{Lo}}-V_{\mathrm{TH}}$

Where $\mathrm{V}_{\mathrm{Lo}}$ is the load voltage magnitude, $\mathrm{Z}_{\mathrm{TH}}$ is the load impedance, $\mathrm{V}_{\mathrm{TH}}$ denotes the system voltage during fault condition and $\mathrm{I}_{\mathrm{Lo}}$ represents the load current which is done by:

$I_{\mathrm{Lo}}=\frac{P_{\mathrm{Lo}}+j Q_{\mathrm{Lo}}}{V_{\mathrm{Lo}}}$

When $\mathrm{V}_{\mathrm{Lo}}$ is considered as a reference equation can be rewritten

$V_{\mathrm{DVR}}=V_{\mathrm{Lo}}^{\angle 0}+Z_{\mathrm{TH}} \angle \beta-\theta \mathrm{I}_{\mathrm{Lo}}{ }^{\angle 0}-V_{\mathrm{TH}}{ }^{\angle \delta}$

$\theta=\tan ^{-1}\left(\frac{\theta_{\mathrm{Lo}}}{P_{\mathrm{Lo}}}\right)$

The complex power injection of DVR can be written as:

$S_{\mathrm{DVR}}=V_{\mathrm{DVR}} I_{\mathrm{Lo}}{ }^{*}$

Only the required reactive power is injected which can be provided by the DVR itself [24].

\section{VOLTAGE STABILITY AND POWER CONTROLLABILITY: SIMULATION RESULTS}

To evaluate the contribution impact of D-FACTS to the PV farms tied to grid, we have chosen the DVR as case of study. The DVR has a power rating of 4MVA and is used to regulate voltage on a $30 \mathrm{kV}$ distribution grid connected to bus B2. One feeder transmits power to a local load connected at bus B3 which represents a plant continuously absorbing fluctuating currents, thus causes voltage flicker. an appropriate voltage is injected by the DVR in order to regulate the voltage of the bus B1 and B3. This voltage transfer is done through the reactance of the coupling transformer by producing a secondary voltage in phase with the primary voltage (grid side).The simulation scenario considered in this case study consists of creating two faults of 0.3 second duration each during a simulation time of three seconds. The first fault is a swell voltage created between 0.8 and 1.1 seconds and the second fault is a sag voltage fault set between 1.25 seconds to 1.55 seconds, as shown in Figure 5. The swell voltage fault is simulated as an increase of $20 \%$ of the nominal voltage while the sag voltage was set to decrease by $10 \%$ of nominal voltage. 


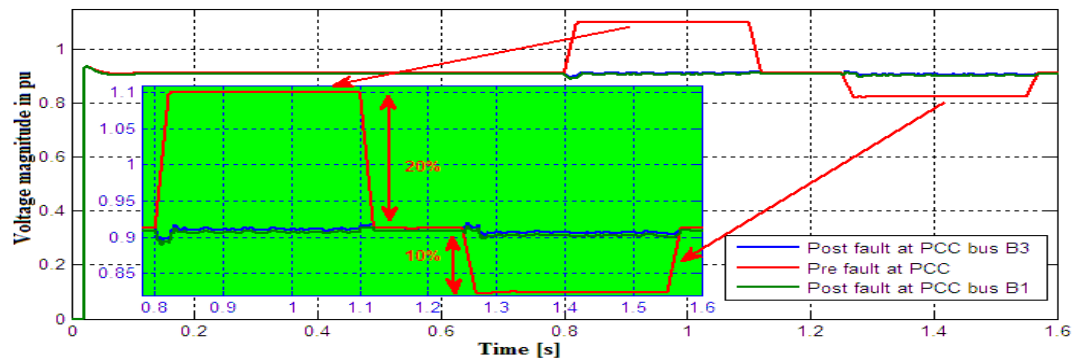

Figure 5. The sag and swell voltage magnitude curves at point common coupling.

The scenarios of simulation are:

- $\quad$ DVR disconnected, and no fault applied.

- $\quad$ DVR disconnected with a fault applied.

- $\quad$ DVR in operation with same scenarios as above.

During normal operation, the dynamic voltage restorer remains in standby mode. When a voltage swell occurs, the control device detects the fault in the sytem and the DVR injects the appropriate voltage as seen in Figures 6, 7 and 8.

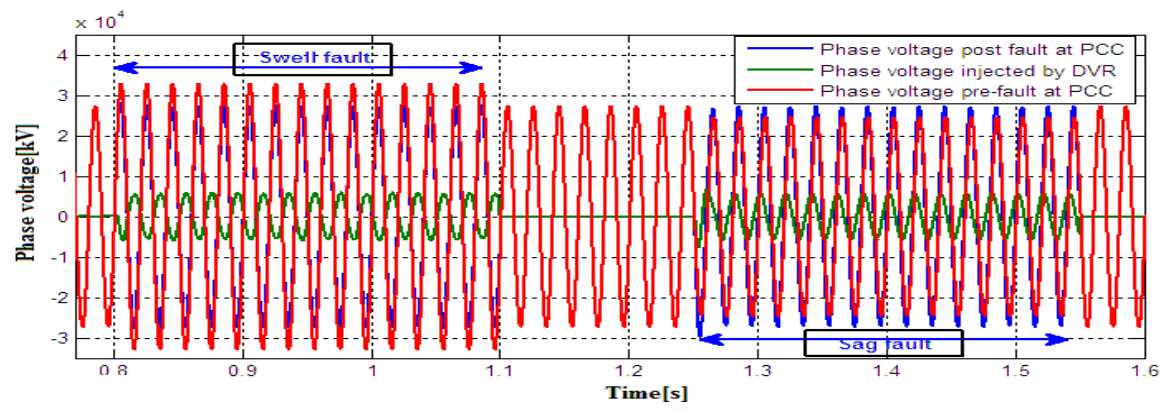

Figure 6. Phase voltage at point common coupling during sag and swell faults.

When the swell voltage happens at 0.8 second, the DVR injects a compensating voltage and after a transient lasting approximately 0.1131 second, the steady state is reached as shown in Figure 7.

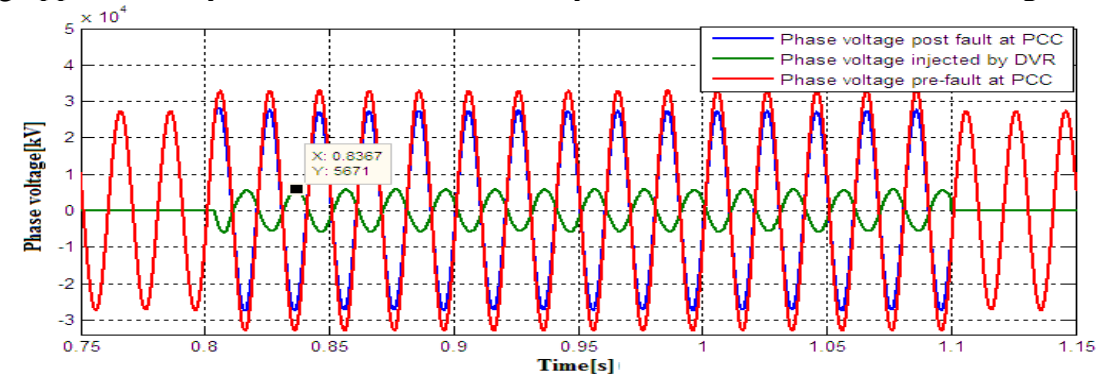

Figure 7. Phase voltage at PCC during swell fault

In the case of voltage sag occurring at 1.25 seconds the grid voltage at the PCC reaches the steady state after 2 cycles which corresponds to approximately 0.036 seconds as seen in Figure 8. 


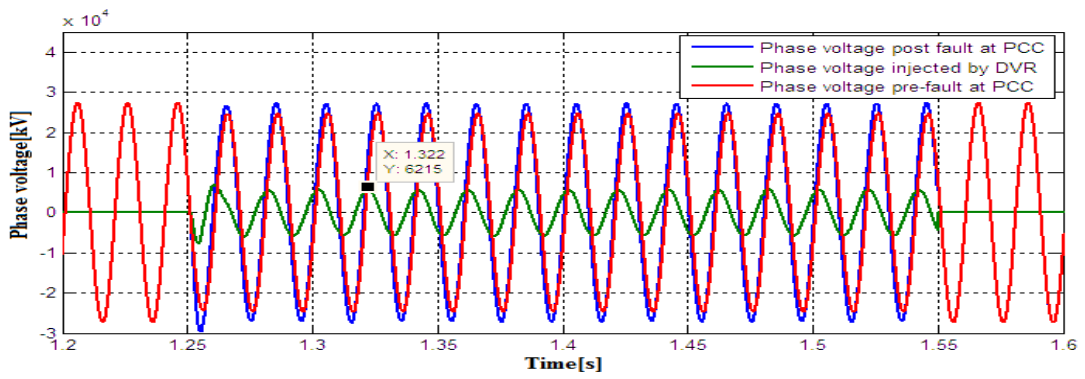

Figure 8. Phase voltage during sag fault at point common coupling

The active and reactive powers are seen in Figures 9 and 10 respectively. In Figure 9 and during the swell fault, we can observe small overshoots and oscillations in the active power for 2 cycles of transient when the DVR is not in operation, but the oscillations are completely damped when the DVR is switched on. For a sag fault and without DVR, the grid voltage exhibits a large transient lasting for 9 cycles which, again, is completely damped when the DVR is introduced.

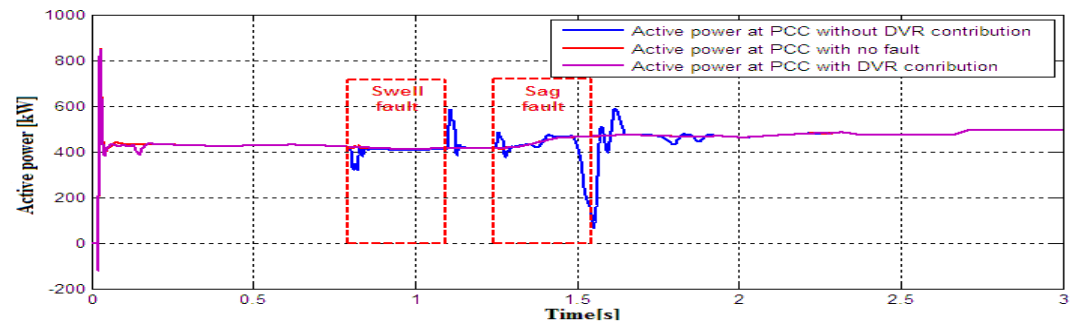

Figure 9. Injected active power PV farms to network

As depicted in Figure 10 the reactive power flow at the PCC during two faults and during the swell fault the oscillations of reactive power are more important as compared to the case of sag fault where the overshoots are smaller in magnitude with the DVR contribution. In the case of voltage sag fault and without the DVR, the flow of reactive power increases in magnitude, direction and duration.

After a short oscillation appearing at the onset of the fault, the reactive power exhibits a large overshoot at 1.39 seconds corresponding to an injection of $+181.2 \mathrm{kVar}$. The reactive power suddenly decreased to $-139.1 \mathrm{kVar}$ at 1.535 seconds, then after several oscillations the system's normal operation is restored at the end of the sag fault at 1.957 seconds compared with the case with DVR contribution where it can be observed that the oscillations have been completely damped at 1.699 seconds.

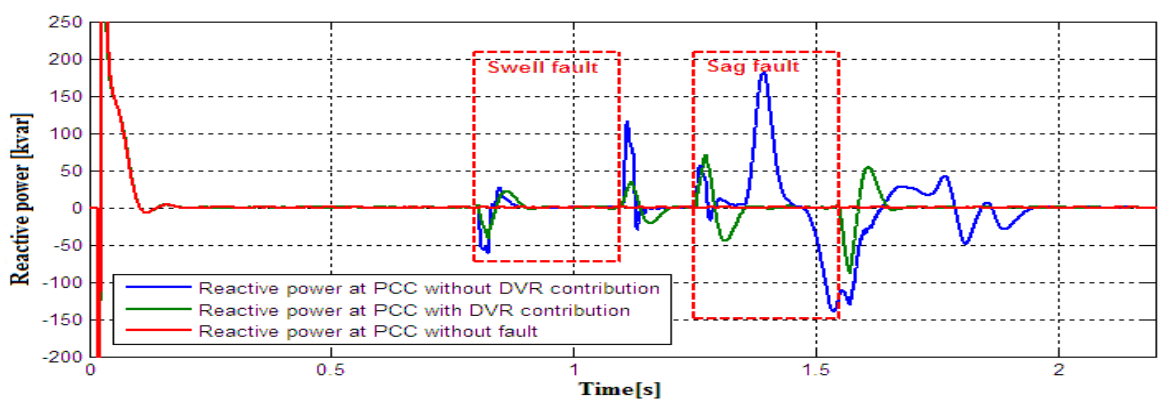

Figure 10. Reactive power flow at PCC

Figure 11 shows the total current supplied from the PV farms to the load and the grid. It can be observed that during voltage swell the current has decreased from $11.26 \mathrm{~A}$ to $9.16 \mathrm{~A}$ in the case where the 
DVR is not in operation. There is a reduction in the current despite a voltage increase (swell fault). This action is due to PV system inverter in order to regulate its voltage at bus B1.Similarly, it can be seen that the same contribution of the PV system inverter at the voltage sag fault when the current has increased from a its normal value of $12.32 \mathrm{~A}$ to $14.72 \mathrm{~A}$ during the fault and suddenly collapses to $4 \mathrm{~A}$ and finally stabilizing after several oscillations. The effective contribution of the DVR in stabilizing the current at its normal value during faults is achieved rapidly and relatively smooth.

Figure 12 illustrates the power factor (PF) behavior at the PCC. Under normal operation the PF is kept at unity by placing $10 \mathrm{kVar}$ capacitor bank filtering harmonics at the VSC output of the PV farms so as to transfer entirely the active power generated by the PV farms to the load and the grid. It is seen in Figure 12 that in the case of voltage swell fault, the operating limits of the system are acceptable. However, without DVR, the voltage sag caused a significant drop in the PF which reached 0.5 at the end of the disturbance.

It can be concluded that the power factor at the point common coupling is effectively controlled by the DVR during the voltage fault scenarios considered. The negative impact of renewable energies on power quality arises mainly from two typical characteristics of renewable energy sources namely their random variability and the presence of a static converter to interface the generating plants to the grid(with exception for hydroelectric) [3]. These devices cause harmonics in the system and they are also very sensitive to distorted voltage waveforms. In normal cases, the inverter connecting the Renewable Energy Conversion Systems (RECS) to the electrical network modifies the output voltage in order to regulate the active and reactive currents between the inverter and the grid and to prevent system from instability due to the widespread deployment of RECS, independent system operators (ISO) require RECS to operate according to strict network codes so that to remain connected to the network and provide the expected reactive current to support the electric system during network faults [6], [25].

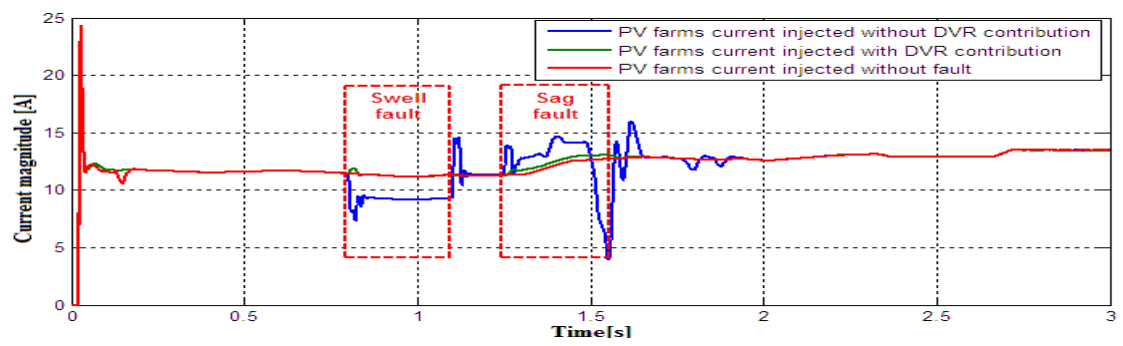

Figure 11. PV farms injected current.

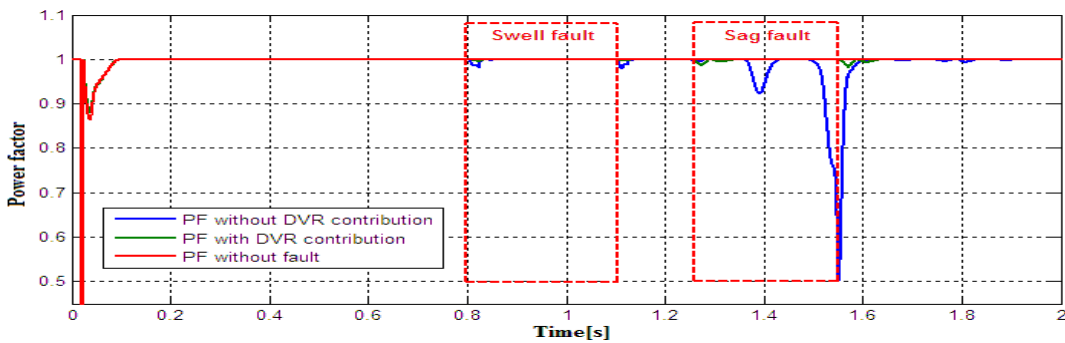

Figure 12. Power factor at PCC.

\section{CONCLUSION}

The results show that the DVR interfaced to photovoltaic systems and tied to grid in medium voltage is effective in reducing voltage sags and swells with improved voltage regulation capabilities and flexibility for power factor correction. Our simulation model presents the dynamic interaction between the DVR converters and the converters of PV system. The Dynamic voltage restorer is one of the fastest and effective custom power device that has proven its effectiveness for the mitigation of voltage sags and swells. The simulation study presented in this work has demonstrated that the DVR is a potential power quality improvement device. 


\section{REFERENCES}

[1] International Energy Agency, "Renewables 2019", IEA, Paris, 2019.

[2] S. Kirmani, M. Jamil, and I. Akhtar, "Economic feasibility of hybrid energy generation with reduced carbon emission," IET Renew. Power Gener., vol. 12, no. 8, pp. 934-942, Nov. 2018.

[3] K. Kaliappan , M. Sankar , B. Karthikeyan , B. Vineeth , V.C. Raju ," Analysis of solar energy technology in leading countries ", International Journal of Power Electronics and Drive System (IJPEDS),Vol. 10, No. 4, pp. 1995-2004, 2019.

[4] A. A. Tadjeddine, A. Chaker, M. Khiat, L. Abdelmalek, N. Khalfalah, "A contribution to the control of voltage and power of the interconnection between two decentralized electrical grids with an optimal localization of the SVC devices in real-time ", International Journal of Power Electronics and Drive System (IJPEDS), Vol. 10, No. 1, pp. 170-177, 2019.

[5] A. Jäger-Waldau, " PV Status Report 2017", EUR 28817 EN, Publications Office of the European Union, Luxembourg, 2017.

[6] A. Benali, M. Khiat, T. Allaoui and M. Denaï, "Power Quality Improvement and Low Voltage Ride Through Capability in Hybrid Wind-PV Farms Grid-Connected Using Dynamic Voltage Restorer ", IEEE Access, vol. 6, pp. 68634-68648, 2018.

[7] H. S. Kamil, D. M. Said, M. W. Mustafa, M.R. Miveh, N. Ahmad, "Low-voltage Ride-through Methods for Gridconnected Photovoltaic Systems in Microgrids: A Review and Future Prospect", International Journal of Power Electronics and Drive System (IJPEDS), Vol. 9, No. 4, pp. 1834 1841, December 2018.

[8] M. A. Mansor, M. M. Othman, I. Musirin, S. Z. M. Noor, "Dynamic voltage restorer (DVR) in a complex voltage disturbance compensation", International Journal of Power Electronics and Drive System (IJPEDS), Vol. 10, No. 4, pp. 2222 2230, December 2019.

[9] S. Suraya, P. Sujatha, P. B. Kumar, " Contemporary Control of DG Integrated DVR for Sag, Swell and Harmonic Mitigation “, International Journal of Electrical and Computer Engineering (IJECE), Vol. 8, No. 5, pp. 2721 2730, October 2018.

[10] A. B. Mohammed, M. A. M. Ariff, S. N. Ramli, "Power quality improvement using dynamic voltage restorer in electrical distribution system: an overview", Indonesian Journal of Electrical Engineering and Computer Science (IJEECS), Vol. 17, No. 1, pp. 86 93, January 2020.

[11] M. Sarvi, H. Marefatjou, " Compensation of Voltage Single-Phase SAG and SWELL Using Dynamic Voltage Restorer and Difference Per-Unit Value Method ", International Journal of Electrical and Computer Engineering (IJECE), Vol.3, No.1, pp. 83-92, February2013

[12] N. S. Srivatchan, P. Rangarajan, "Half Cycle Discrete Transformation for Voltage Sag Improvement in an Islanded Microgrid Using Dynamic Voltage Restorer", Vol. 9, No. 1, pp. 25 32, March 2018.

[13] M. M. Othman, N. M. Rakami, Z. Abdul Hamid, I. Musirin, M. L. Othman, "Energy efficiency enhancement using dynamic voltage restorer (DVR)", International Journal of Power Electronics and Drive System (IJPEDS), Vol. 10, No. 3, pp. 1308 1316, Sep 2019.

[14] D. V. Chinmay, D. V. Chaitanya, "Optimum design of dynamic voltage restorer for voltage sag mitigation in distribution network", Vol. 10, No. 3, pp. 1364 1372, Sep 2019.

[15] N. Femia. G. Petrone, G. Spagnuolo, M. Vitelli, " Power Electronics and Control Techniques for Maximum Energy Harvesting in Photovoltaic Systems". CRC press 1st ed, 2013.

[16] H. Madhusudan Shertukde, " Distributed Photovoltaic Grid Transformers". CRC Press, 1st ed., 2014.

[17] M. C. Di Piazza and G. Vitale, " Photovoltaic Sources Modeling and Emulation, Green Energy and Technology ", Springer-Verlag London, 1st ed., p53, 2013.

[18] D. Verma, S. Nema, A. M. Shandilya, S. K. Dash, "Maximum Power Point Tracking MPPT Techniques: Recapitulation in solar photovoltaic systems", Renewable and Sustainable Energy Reviews, vol. 54, pp. 1018-1034, 2016.

[19] H. Abu-Rub, M. Malinowski, K. Al-Haddad,"Power Electronics for Renewable Energy", John Wiley \& Sons Ltd, 1 st ed., 2014.

[20] N. Mohan, Power Electronics, John Wiley \& Sons Ltd, 1st ed., 2012.

[21] Q. Zhong, T. Hornik, " Control of Power Inverters in Renewable Energy and Smart Grid Integration", John Wiley \& Sons Ltd ,1st ed., pp.59-60, 2013.

[22] B. Dokić, B. Blanuša, " Power Electronics Converters and regulators ", Springer, 3st ed., 2015.

[23] N. Mohan, Tore M. Undeland, William P. Robbins, " Power Electronics Converters Applications Design", John Wiley \& Sons Ltd, 3st ed.,2003.

[24] E. Acha, V.G. Agelidis, O. Anaya-Lara, T.J.E. Miller, "Power Electronic Control in Electrical Systems", Newnes, 1st ed.,2002.

[25] L. Ruiqi, G. Hua, Y. Geng, " Fault ride-through of renewable energy conversion systems during voltage recovery ", J. Mod. Power Syst. Clean Energy, vol. 4, no. 1, pp. 28-39,2016. 


\section{BIOGRAPHIES OF AUTHORS}

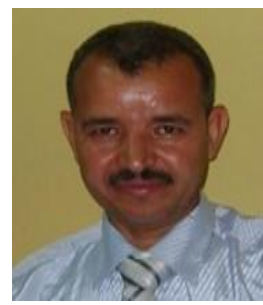

Abdelkrim Benali is a Professor in the Department of Electrical Engineering at NOUR Bachir university center, in El Bayadh, Algeria. He received a doctorate degree in Electrotechnics from the Polytechnic National School of Oran (ENPO), Algeria. His research activities include FACTS devices, renewable energy and distributed energy resources modeling and conception, renewable energy grid integration. He is a member of the "SCAMRE" laboratory.

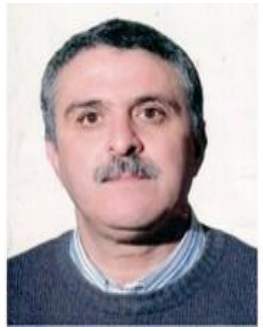

Mounir Khiat is a Professor in the Department of Electrical Engineering at the Polytechnic National School of Oran (ENPO), Algeria. He received a doctorate degree in Electrotechnics from the University of USTO, Oran. Member of the "SCAMRE" laboratory. His research activities include the control of large electric power systems, multi machine, multi converter systems, FACTS devices, HVDC systems, renewable energy and distributed energy resources, modeling and conception, real time simulation of power systems and smart grids. His teaching includes neural process control and real time simulation of power systems.

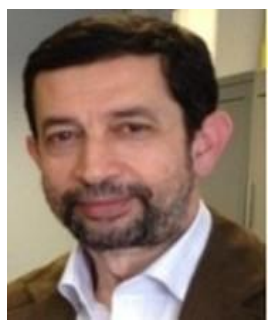

Mouloud Denai graduated from the University of Science and Technology of Algiers and Ecole Nationale Polythechnique of Algiers, Algeria in Electrical Engineering and received his $\mathrm{PhD}$ in Control Engineering from the University of Sheffield, UK. He worked for the University of Science and Technology of Oran (Algeria) until 2004 and the University of Sheffield (UK) from 2004 to 2010. From 2010 to 2014, he worked for the University of Teesside (UK). He is currently with the University of Hertfordshire (UK) since 2014. His main fields of expertise are in modeling, optimization and control of engineering and life science (biological and biomedical) systems. His current research interests in energy include intelligent control design and computational intelligence applications to efficiency optimization in renewable energy systems with particular focus in the management of smart homes and dynamic scheduling, optimization and control of future smart grids. , condition monitoring and asset management in electric power networks; Energy storage systems integration into the grid; Smart meter data analytics using machine learning techniques for efficient energy management; electric vehicles integration into the distribution grid and V2G/G2V management. 